\title{
ARISTOLOCHIA BRACTEOLATA - ANTIHYPERGLYCEMIC AND ANTIHYPERLIPIDEMIC ACTIVITY IN DEXAMETHASONE-INDUCED DIABETIC RAT MODEL
}

\author{
GANGA RAJUM*, HEMA SUNDAR REDDY T \\ Department of Pharmacology, Gokaraju Rangaraju College of Pharmacy, Hyderabad, Telangana, India. Email: mgrpharma@gmail.com
}

Received: 07 March 2017, Revised and Accepted: 24 April 2017

\begin{abstract}
Objective: The present study was aimed to evaluate antihyperglycemic and antihyperlipidemic activities of methanolic extract of Aristolochia bracteolata (MEAB) against dexamethasone-induced diabetic rat model.
\end{abstract}

Methods: Methanolic extract was prepared by soxhlet extraction and was evaluated for antihyperglycemic and antihyperlipidemic activity using dexamethasone-induced model. The MEAB was administered orally at a dose of 200 and $400 \mathrm{mg} / \mathrm{kg}$ body weight glibenclamide was used as standard drug. On $0^{\text {th }}$ and $11^{\text {th }}$ day, blood was collected by retro-orbit plexus.

Results: In this model blood glucose levels were determined on $0^{\text {th }}$ and $11^{\text {th }}$ days and MEAB significantly reduced the blood glucose levels in diabetic rats. The effect of MEAB on serum lipid profile such as total cholesterol (TC), triglycerides (TGs), low-density lipoprotein (LDL), very LDL (VLDL), and high-density lipoprotein (HDL) was also measured on the $11^{\text {th }}$ day in the diabetic rats. Significant reduction in TC, TGs, LDL, and VLDL levels and improvement in HDL level were observed in diabetic rats.

Conclusion: From the results, it was found that the MEAB possess antihyperglycemic and antihyperlipidemic activities.

Keywords: Aristolochia bracteolata, Glibenclamide, Antihyperglycemic, Antihyperlipidemic, Dexamethasone.

(C) 2017 The Authors. Published by Innovare Academic Sciences Pvt Ltd. This is an open access article under the CC BY license (http://creativecommons. org/licenses/by/4. 0/) DOI: http://dx.doi.org/10.22159/ajpcr.2017.v10i8.18328

\section{INTRODUCTION}

Diabetes mellitus is a chronic disease caused by inherited or acquired deficiency in the production of insulin by the pancreas or by the ineffectiveness of the produced insulin. Such a deficiency results in increased concentrations of glucose in the blood, which in turn damage many of the body's systems, in particular, the blood vessels and nerves [1]. Over $90 \%$ of patients with diabetes have Type 2 diabetes; the remainder has Type 1 diabetes. According to the recent data from the World Health Organization and International Diabetes Federation, the number of people affected with diabetes worldwide has increased dramatically over recent years. Currently, there are over 366 million diabetics worldwide, and this is likely to increase to 552 million more by the year 2030 [2,3]. Diabetes mainly characterized by hyperglycemia, ketoacidosis, and hypertriglyceridemia. The characteristic symptoms of diabetes are polyuria, polydipsia, polyphagia, and unexpected weight loss [4]. Abnormalities in lipid profile are one of the most common complications in diabetes mellitus, which is found in about $40 \%$ of diabetes patients [5]. Diabetes induction causes an increase in cholesterol, triglycerides (TGs), low-density lipoprotein (LDL), and very LDL (VLDL) [6]. The levels of serum lipids are usually elevated in diabetes mellitus, and such an elevation represents the risk factor for coronary heart disease [7]. Management of diabetes without any side effect is still a challenge to the medical community.

The ethnomedicine and ethnopharmacology remedies have gained popularity among the people of developing countries, being safe, effective, and inexpensive [8]. Aristolochia bracteolata belongs to the family Aristolochiaceae [9]. A literature survey revealed that methanolic extract of whole plant of $A$. bracteolata is endowed with various chemical components such as phenolic compounds, flavonoids, triterpenoids, alkaloids, steroids, cardiac glycosides, saponins, aristolochic acid-A, and aristolochic acid-D. A. bracteolata is an herbal medicine for the treatment of various diseases such as gastric stimulant, anti-inflammatory agents, antifungal, antibacterial activity, and cancer [10].
The present study is carried out to investigate the effect of oral administration of methanolic extract of whole plant of A. bracteolata on blood glucose levels and lipid profile in dexamethasone in induced diabetic rats.

\section{MATERIALS AND METHODS}

\section{Materials}

Dexamethasone was purchased from SVR Chemicals Ltd., (Hyderabad). Glucose kit and lipid profile kits were purchased from K. K. Diagnostics (Hyderabad). All other chemicals were obtained from the Dwarakamai Enterprises (Hyderabad).

\section{Animals}

Adult Wistar albino rats (150-200 g) were used for the present study. They were kept in polypropylene cages at $25 \pm 2^{\circ} \mathrm{C}$, with relative humidity $45-55 \%$ under 12 hrs light and dark cycles. All the animals were acclimatized to the laboratory conditions for a week before use. They were fed with standard animal feed and water ad libitum. All the pharmacological experimental protocols were approved by the Institutional Animal Ethics Committee (IAEC) (Reg. No. 1175/PO/ Ere/S/08/CPCSEA), Gokaraju Rangaraju College of Pharmacy.

\section{Preparation of extract}

The plant A. bracteolata was collected in January 2016 from the Nallamala Forest region, Velugodu, Kurnool district. The procured plant materials were authenticated by a botanist. The whole plant was washed, dried at room temperature in the dark and then, finely grind to a powder. Then, the powder was extracted with the methanol in the ratio of $1: 6$ by simple distillation technique. The solvent was completely removed under reducing pressure, and a semisolid mass (yield: 9.4\%, $\mathrm{w} / \mathrm{w}$ ) was obtained and stored for further study.

\section{Preliminary phytochemical analysis}

The preliminary phytochemical studies were performed for testing different chemical groups present in MEAB. Phytochemical screening 
gave positive results for phenolic compounds, flavonoids, triterpenoids, alkaloids, steroids, cardiac glycosides, and saponins [11].

\section{Acute toxicity study}

The acute oral toxicity [12] study was carried out as per the guidelines set by the Organization for Economic Co-operation and Development, the study was approved by the IAEC. No mortality and no signs of toxicity were found even after administration of a limit dose of $2000 \mathrm{mg} / \mathrm{kg}$ body weight of extract; hence, $1 / 10^{\text {th }}$ of the dose was taken as effective dose. Two doses, 200 and $400 \mathrm{mg} / \mathrm{kg}$ were selected for the present study to evaluate antihyperglycemic and antihyperlipidemic activity.

\section{Dexamethasone-induced diabetic rat model}

Diabetes was induced in healthy Wistar albino rats using dexamethasone at a dose of $10 \mathrm{mg} / \mathrm{kg}$, body weight subcutaneous (s.c) for 10 days. Treatment was continued for 10 consecutive days with dexamethasone. The animals were randomly divided into five groups of six animals in each group. Group - I received saline (normal control), Group - II received dexamethasone $10 \mathrm{mg} / \mathrm{kg}$, s.c (diabetic control), Group - III received dexamethasone $10 \mathrm{mg} / \mathrm{kg}$, s.c and MEAB $(200 \mathrm{mg} / \mathrm{kg}$ body weight), Group - IV received dexamethasone $10 \mathrm{mg} / \mathrm{kg}$ s.c and MEAB (400 mg/kg body weight), and Group - V dexamethasone $10 \mathrm{mg} / \mathrm{kg}$, s.c and glibenclamide $(0.5 \mathrm{mg} / \mathrm{kg})$. On the $11^{\text {th }}$ day, blood was withdrawn from the animals and subjected for the analysis of blood glucose and all biochemical parameters such as total cholesterol (TC), TG, LDL, and VLDL and high-density lipoprotein (HDL) levels. The levels of the biochemical parameters in the treated groups were compared with that of diabetic control group [13]

\section{Statistical analysis}

All results were expressed as the mean \pm standard error mean. The results were analyzed for statistical significance by one-way ANOVA followed by Dunnett's test using GraphPad Prism version 5.0 (Graph Pad Software, USA).

\section{RESULTS}

\section{Phytochemical screening}

The preliminary phytochemical screening of the A. bracteolata showed the presence of phenolic compounds, flavonoids, triterpenoids, alkaloids, steroids, cardiac glycosides, and saponins.

\section{Dexamethasone-induced diabetic rat model}

The parameters such as body weight, blood glucose level, and lipid profile parameters of normal control group; diabetic control group, standard group (glibenclamide $0.5 \mathrm{mg} / \mathrm{kg}$ ), and MEAB were summarized in Tables 1-3.

\section{Effect of extract on body weight}

The body weight of the normal and treated groups significantly differ from diabetic control on the $11^{\text {th }}$ day shown in Table 1 . The treated groups of animal body weight maintained throughout the experiment compare to diabetic control.

\section{Effect of extract on blood glucose level}

Blood glucose level was found to be increased in dexamethasoneinduced diabetic rats significantly when compared to control. The MEAB and standard drug treated groups had shown a significant decrease in blood glucose level when compared to diabetic control group. The results were tabulated in the Table 2 , respectively.

\section{Effect of extract on blood lipid profile}

The diabetes-induced hyperlipidemia was reversed significantly when compared to diabetic control which was depicted in the Table 3. A significant percentage reduction of TC level, LDL, TG, and VLDL in extract treated group was significant when compared to diabetic group. However, HDL levels increased with treatment of extract and standard group, respectively.
Table 1: Effect of MEAB on body weight by dexamethasone-induced diabetic rats

\begin{tabular}{llll}
\hline Group & Treatment & \multicolumn{2}{l}{$\begin{array}{l}\text { Body weight }(\mathrm{g}) \\
\text { mean } \pm \text { SEM }\end{array}$} \\
\cline { 3 - 4 } & & $\mathbf{0}^{\text {th }}$ day & $\mathbf{1 1}^{\text {th }}$ day \\
\hline I & Normal control & $166.5 \pm 2.125$ & $176.1 \pm 2.358$ \\
II & Diabetic control & $165.5 \pm 2.109$ & $147.3 \pm 2.951$ \\
III & MEAB200 $\mathrm{mg} / \mathrm{kg}$ & $168.6 \pm 1.926$ & $172.3 \pm 1.498^{*}$ \\
IV & MEAB400 $\mathrm{mg} / \mathrm{kg}$ & $169.8 \pm 1.661$ & $174.5 \pm 1.565^{* *}$ \\
$\mathrm{~V}$ & Glibenclamide 0.5 mg/kg & $167.1 \pm 1.887$ & $172.8 \pm 1.990^{* *}$ \\
\hline Values are mean $\pm S E M, \mathrm{n}=6$ when compared with control ${ }^{*} \mathrm{p}<0.05,{ }^{* *} \mathrm{p}<0.01$. \\
SEM: Standard error mean, MEAB: Methanolic extract of Aristolochia \\
bracteolata
\end{tabular}

Table 2: Antihyperglycemic activity of MEAB on dexamethasone-induced diabetic rats

\begin{tabular}{llll}
\hline Group & Treatment & \multicolumn{2}{l}{$\begin{array}{l}\text { Blood glucose levels } \\
(\mathbf{m g} / \mathbf{d L}) \\
\text { mean } \pm \text { SEM }\end{array}$} \\
\cline { 3 - 4 } & & $\mathbf{0}^{\text {th }}$ day & $\mathbf{1 1}^{\text {th }}$ day \\
\hline I & Normal control & $84.5 \pm 2.446$ & $85.1 \pm 2.482$ \\
II & Diabetic control & $84.6 \pm 2.859$ & $235.8 \pm 1.740$ \\
III & MEAB $(200 \mathrm{mg} / \mathrm{kg})$ & $84.8 \pm 3.048$ & $124.5 \pm 1.231^{*}$ \\
IV & MEAB $(400 \mathrm{mg} / \mathrm{kg})$ & $87.6 \pm 2.304$ & $116.6 \pm 1.115^{* *}$ \\
$\mathrm{~V}$ & Glibenclamide $(0.5 \mathrm{mg} / \mathrm{kg})$ & $86.3 \pm 3.639$ & $105.1 \pm 1.351^{*}$ \\
\hline Values are mean $\pm S E M, \mathrm{n}=6$ when compared with control ${ }^{*} \mathrm{p}<0.05,{ }^{* *} \mathrm{p}<0.01$. \\
SEM: Standard error mean, MEAB: Methanolic extract of Aristolochia \\
bracteolata
\end{tabular}

\section{DISCUSSION}

Dexamethasone is a potent glucocorticoid. Glucocorticoids are widely used therapeutic tools, particularly in treatment for anti-inflammatory and immunomodulatory purposes. Side effects of glucocorticoid treatment include steroid diabetes. Glucocorticoid-induced hyperglycemia is partially due to increased hepatic glucose production and insulin resistance of peripheral tissues. Moreover, glucocorticoids are known to inhibit insulin secretion.

Glibenclamide has been used for many years to treat diabetes to stimulate insulin secretion from pancreatic $\beta$-cells. In general diabetic rats show lower body weight, high blood glucose, and lipid levels as compared to normal rats. The present data indicated that MEAB at 200 and $400 \mathrm{mg} / \mathrm{kg}$ significantly reduced the elevated fasting blood glucose levels and increased body weight in a dose-dependent manner in diabetic animals

The possible mechanism by which MEAB reduced hypoglycemic action might be due to the presence of phenolic and flavonoids. These phytochemical constituents might be increasing either the pancreatic secretion of insulin from $\beta$-cells of islets of Langerhans or increased peripheral utilization of glucose $[13,14]$.

Lipids play a vital role in the pathogenesis of diabetes mellitus. The levels of serum lipids are usually elevated in diabetes cases, and such an elevation represents the risk factor of coronary heart disease. High levels of TC and more importantly LDL-cholesterol in blood are major coronary risk factor [15]. The abnormal high concentration of serum lipids in the diabetic subjects is due, mainly to the increase in the mobilization of free fatty acids from the peripheral fat depots. Acute insulin deficiency initially causes an increase in free fatty acid mobilization from adipose tissue. The most common lipid abnormalities in diabetes are hypertriglyceridemia and hypercholesterolemia. 
Table 3: Antihyperlipidemic activity of MEAB on dexamethasone-induced diabetic rats

\begin{tabular}{|c|c|c|c|c|c|c|}
\hline \multirow[t]{2}{*}{ Group } & \multirow[t]{2}{*}{ Treatment } & \multicolumn{5}{|c|}{ Lipid profile (mg/dL) } \\
\hline & & TC & TG & HDL & LDL & VLDL \\
\hline I & Normal control & $92.5 \pm 1.384$ & $74.16 \pm 1.327$ & $37.50 \pm 1.945$ & $40.16 \pm 2.194$ & $14.83 \pm 0.265$ \\
\hline III & MEAB (200 mg/kg) & $122.16 \pm 0.792^{* *}$ & $101.83 \pm 0.833^{* *}$ & $31.83 \pm 1.621^{* *}$ & $69.96 \pm 1.456^{* *}$ & $20.36 \pm 0.166^{* *}$ \\
\hline IV & MEAB (400 mg/kg) & $103.33 \pm 1.145^{*}$ & $86.33 \pm 1.498^{*}$ & $36 \pm 1.125^{*}$ & $50.06 \pm 1.757^{*}$ & $17.26 \pm 0.299 *$ \\
\hline V & Glibenclamide $(0.5 \mathrm{mg} / \mathrm{kg})$ & $98.33 \pm 0.714^{*}$ & $81 \pm 0.856^{*}$ & $36.83 \pm 1.42^{*}$ & $45.3 \pm 1.019^{*}$ & $16.2 \pm 0.171^{*}$ \\
\hline
\end{tabular}

cholesterol, TG: Triglyceride, LDL: Low-density lipoprotein, VLDL: Very low-density lipoprotein, HDL: High-density lipoprotein

The MEAB at 200 and $400 \mathrm{mg} / \mathrm{kg}$ significantly reduced the elevated levels of TC, TGs, LDL, and VLDL and also increases the HDL levels in a dose-dependent manner in diabetic animals. The presence of phytochemical constituents such as phenolic, flavonoids, and triterpenoids may be responsible for the activity. These phytochemicals might have decreased cholesterol genesis and blood glucose levels [16].

\section{CONCLUSION}

The results of the present investigation are quite encouraging on oral administration of MEAB at a dose of 200 and $400 \mathrm{mg} / \mathrm{kg}$ body weight for 11 days in dexamethasone-induced diabetic rats. There was a significant decrease in elevated blood glucose levels when compared with diabetic control group. MEAB has also lowered the TC, TGs, LDL, and VLDL levels and increased the levels of HDL when compared to that of the diabetic control group in a dose-dependent manner. The present study revealed that MEAB possesses significant antihyperglycemic and antihyperlipidemic activity. However, further studies are required to confirm the exact mechanism of action and to isolate the phytochemical constituents responsible for these activities.

\section{ACKNOWLEDGMENT}

The authors wish to thank Management and Principal of Gokaraju Rangaraju College of Pharmacy for providing the laboratory facilities for the study.

\section{REFERENCES}

1. American Association of Diabetes Educators. Intensive diabetes management: Implications of the DCCT and UKPDS. Diabetes Educ 2002;28(5):735-40.

2. Whiting DR, Guariguata L, Weil C, Shaw J. IDF diabetes atlas: Global estimates of the prevalence of diabetes for 2011 and 2030. Diabetes Res Clin Pract 2011:94(3):311-21.

3. Reddy NV, Raj GB, Raju M, Anarthe SJ. Antihyperlipidemic activity of Cassia fistula bark using high fat diet induced hyperlipidemia. Int $\mathbf{J}$ Pharm Pharm Sci 2015;7(10):61-4.
4. Prout TE, Malaisse WJ, Pirart J. Proceedings VIII Congress of International Diabetes Federation. Amsterdam: Excerpta Medica; 1974. p. 162.

5. Ravi K, Rajasekaran S, Subramanian S. Antihyperlipidemic effect of Eugenia jambolana seeds kernel on streptozotocin-induced in rats. Food Chem Toxicol 2005;3:1433-9.

6. Soltani N, Keshavarz M, Dehpour AR. Effect of oral magnesium sulfate administration on blood pressure and lipid profile in streptozotocin diabetic rat. Eur J Pharmacol 2007;560:205-51.

7. Rajasekaran S, Ravi K, Sivagnanam K, Subramanian S. Beneficial effects of Aloe veraleaf gel extract on lipid profile status in rats with streptozotocin diabetes. Clin Exp Pharmacol Physiol 2006;33(3):232-7.

8. Galuppo M, Giacoppo S, Bramanti P, Mazzon E. Use of natural compounds in the management of diabetic peripheral neuropathy. Molecules 2014;19(3):2877-95.

9. Thirumal M, Vadivelan R, Kishore G, Brahmaji VS. Aristolochia bracteolata: An overview on pharmacognostical, phytochemical and pharmacological properties. Crit Rev Pharm Sci 2012;1(1):70-82.

10. Devi KB, Kanimozhi S, Suganyadevi P. Phytochemical screening and biological property of Aristolochia bracteolata. J Pharm Res 2011;4(5):1509-14.

11. Khandelwal KR. Practical Pharmacognosy Techniques and Experiments. Pune: Nirali Prakashan; 2005. p. 30-149.

12. OECD. Guideline for Testing of Chemicals No. 425. Paris: OECD; 2001. p. 1-26.

13. Paramesha B, Kumar VP, Ramudu B, Manasa K, Tamilanban T. Antidiabetic and hypolipidaemic activity of Ceiba pentandra, Amaranthus viridis and their combination on dexamethasone induced diabetic Swiss albino rats. Int J Pharm Pharm Sci 2014;6(4):242-6.

14. Azeez OH, Kheder AE. Effect of Gundelia tournefortii on some biochemical parameters in dexamethasone-induced hyperglycemic and hyperlipidemic mice. Iraqi J Vet Sci 2012;26(2):73-9.

15. Reddy NV, Aveti S, Anjum M, Raju MG. Anti-hyperlipidemic activity of methanolic extract of Syzygium alternifolium bark against high-fat diet and dexamethasone-induced hyperlipidemia in rats. Asian J Pharm Clin Res 2015;8(6):165-8.

16. Velmurugan C, Anurag B, Kumar TS, Sharma S. Antihyperglycemic and hypolipidemic activity of leaves of Gossypium herbaceum by dexamethasone induced diabetic rat model. Int J Res Pharm Nano Sci 2013;2(2):169-76. 